\title{
Influence of Thermomecaniques Treatments on the Proprietes of Al-5.8\%Zn-2.7\%Mg Alloy
}

\author{
Mazouz Hamoudi, Bensaada Said, Mohamed Tewfik Bouziane
}

Laboratoire LARHYSS, Université de Biskra, Biskra, Algeria.

Email: bensaada52@yahoo.fr

Received February $19^{\text {th }}, 2012$; revised April $15^{\text {th }}, 2012$; accepted June $11^{\text {th }}, 2012$

\begin{abstract}
The aim of this work is the demonstration of the effect of thermomechanical treatments on the properties of the alloy Al- $5.8 \% \mathrm{Zn}-2.7 \% \mathrm{Mg}$ by thermal analysis techniques and calorimetry, which are methods of test widely used for research purposes and quality control. The effects of thermomechanical treatments on the two variables namely the coefficient of thermal expansion and heat capacity, we can provide further information for better understanding of the phenomena responsible for the thermodynamic behavior of the alloy. The results showed the one hand, there is great similarity between the linear coefficient of thermal expansion and heat capacity, and secondly the effect of plastic deformation is evidenced by changes in the shape of the curves from the rough. Similarly the kinetics of precipitation of $\eta$ phase is accelerated in the case of samples homogenized and homogenized + distorted and accompanied by a shift in the temperature range to lower temperatures than those recorded in the case of the material state Gross.
\end{abstract}

Keywords: Aluminum Alloys; Thermomechanical Treatments; Linear Coefficient of Thermal Dilation; Heat Capacity; Precipitation

\section{Introduction}

Despite the importance of work in this area, aluminum alloys continue to be the center of interest of several research projects in materials science. Their use in the automotive and aerospace industries depends heavily on their mechanical and thermal characteristics. By using different types of heat treatment and thermomechanical can get a wide spectrum of mechanical properties. For conditions of employment data, the thermomechanical treatment of alloys requires a perfect knowledge of changes in thermodynamic properties it entails.

The continuing development of modern techniques, the complication and expansion of requirements to be met by metal alloys have different properties and qualities that are even today the study of thermomechanical processing is experiencing continued growth. New modes of heat treatment, thermomechanical and thermochemical alloys should be designed to meet the requirements of modern industry. In this work, we propose to study the behavior dilatometry and calorimetry (DSC) of the alloy $\mathrm{Al}-5.8 \% \mathrm{Zn}-2.7 \% \mathrm{Mg}$ in different thermomechanical states.

\section{Experimental Methods}

The alloy Al-5.8\%Zn-2.7\%Mg was prepared by the con- ventional method of casting ingots by melting in an induction furnace from Leybold. The fusion is performed in refractory crucibles $\left(\mathrm{Al}_{2} \mathrm{O}_{3}\right)$. Its chemical composition is shown in Table 1.

The temperatures and durations of heat treatments are shown in Table 2.

The analytical techniques used in this regard are the dilatometer and the DCS. It should be noted that all heat treatments were performed in a furnace summers type Adamel or the temperature gradient is about $+/-2^{\circ} \mathrm{C}$.

- The first sample is in the rough cast of [B] (Figure 1(a)).

- The second underwent a homogenization annealing [H] at $T=465^{\circ} \mathrm{C}$ and held for 20 hours, then quenched in water $\left(20^{\circ} \mathrm{C}\right)$ (Figure 1(b)).

- The third sample, in addition to the homogenization treatment, the alloy was cold rolled $(E=20 \%)[\mathrm{H}+\mathrm{D}]$ (Figure 1(c)).

\section{Results and Discussion}

\subsection{Dilatometric Study of the Sample in the Rough}

The Figure 2 shows the variation of the linear coefficient of thermal expansion $\alpha$ of the alloy $\mathrm{Al}-5.8 \% \mathrm{Zn}-2.7 \% \mathrm{Mg}$ in the raw state as a function of temperature in the 
Table 1. Chemical composition of the alloy Al-5.8\% Zn-2.7\%Mg.

\begin{tabular}{ccccccccc}
\hline Elément & Al & Zn & Mg & Cu & Zr & Fe & Si \\
\hline \%en poids & 91.45 & 5.8 & 2.7 & 0.01 & 0.01 & 0.01 & 0.01 \\
\hline
\end{tabular}

Table 2. Temperature and duration of heat treatments.

\begin{tabular}{cccc}
\hline Alliage & Type des traitements thermiques & Température $\left({ }^{\circ} \mathbf{C}\right)$ & Temps de maintien (h) \\
\hline & Homogénéisation & 465 & 20 \\
Al- $5.8 \% \mathrm{Zn}-2.7 \% \mathrm{Mg}$ & Trempe & 20 & Variable \\
\hline
\end{tabular}

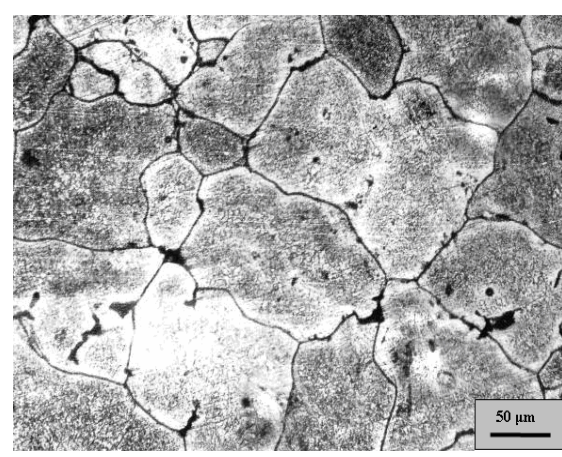

(a)

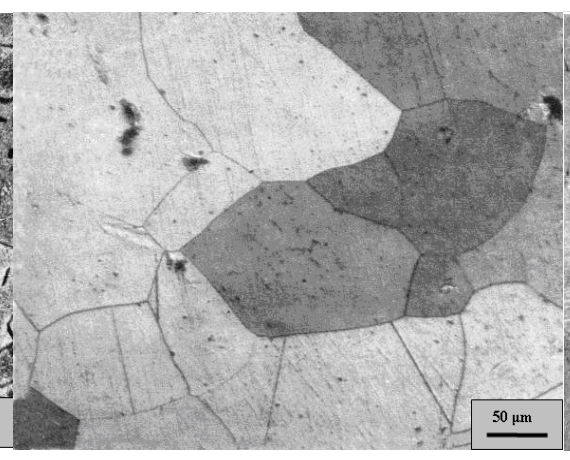

(b)

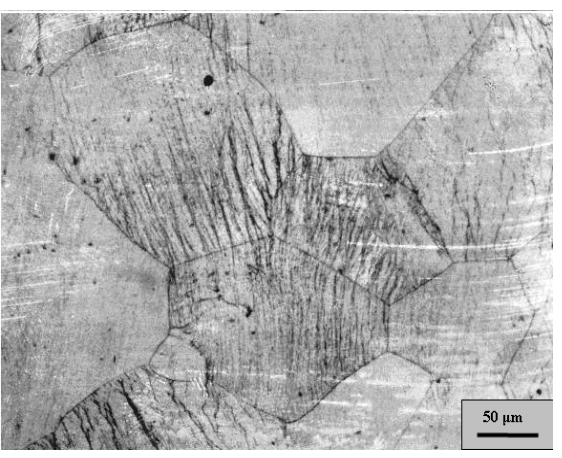

(c)

Figure 1. Microstructure of samples of the alloy Al-5.8\%Zn-2.7\%Mg: (a) Gross State (B); (b) State Homogenized (H) and (c) Deformed State + Homogenized (H + D).

\begin{tabular}{cc}
\hline Transformations & Domaine de température ${ }^{\circ} \mathbf{C}$ \\
\hline Expansion & $90-125$ \\
Contraction & $175-225$ \\
Expansion & $270-300$ \\
Expansion & $350-400$ \\
\hline
\end{tabular}

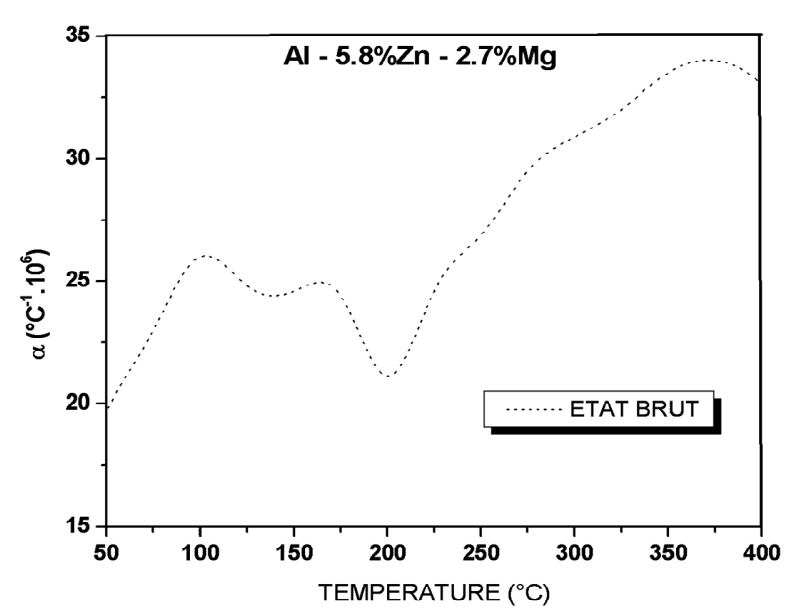

Figure 2. Variation of $\alpha$ as a function of $T^{\circ} \mathrm{C}$ of the alloy $\mathrm{Al}-5.8 \% \mathrm{Zn}-2.7 \% \mathrm{Mg}$ in the rough. interval $\left[50^{\circ} \mathrm{C}-400^{\circ} \mathrm{C}\right]$. It is observed that occurs four (04) transformations corresponding to different temperature ranges and is characterized by the peaks.

\subsection{Calorimetric Study of the Sample in the Rough}

The Figure 3 shows the change in the DSC curve of the alloy $\mathrm{Al}-5.8 \% \mathrm{Zn}-2.7 \% \mathrm{Mg}$ in the raw state as a function of temperature and in the interval $\left[50^{\circ} \mathrm{C}-400^{\circ} \mathrm{C}\right]$.

It is observed that occurs three (03) transformations corresponding to peaks:

One might think at first approach as the first three transformations, there is a similarity between the results found by both experimental techniques. There is a gap of about twenty degrees $\mathrm{C}$ for there to be a perfect overlap of the results found by the techniques of dilatometry and calorimetry. The work of Deschamps et al. [1] and Benabdoun [2] suggest that this discrepancy is certainly due to poor calibration of the DSC. By cons for the fourth processing corresponding to the third expansion observed in the temperature range $350^{\circ} \mathrm{C}-400^{\circ} \mathrm{C}$, we find no confirmation by a peak in this temperature range.

- The first peak, endothermic, is the first expansion observed on the dilatometric curves and can be attributed to the dissolution of Guinier and Preston zones 


\begin{tabular}{cc}
\hline Pics & Domaine de température ${ }^{\circ} \mathbf{C}$ \\
\hline Endothermique & $100-140$ \\
Exothermique & $200-240$ \\
Exothermique & $260-280$ \\
\hline
\end{tabular}

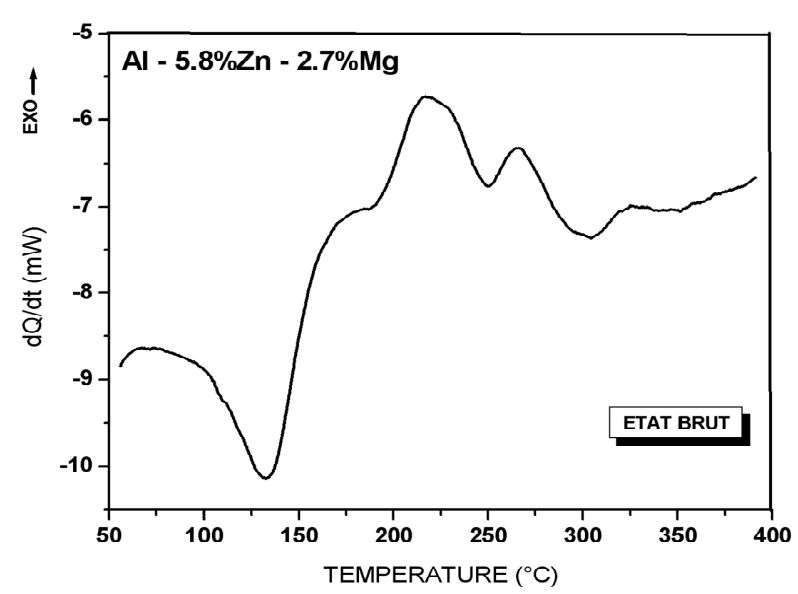

Figure 3. Variation of the DCS as a function of $T^{\circ} \mathrm{C}$ of the alloy $\mathrm{Al}-5.8 \% \mathrm{Zn}-2.7 \% \mathrm{Mg}$ in the rough.

[3-7].

- The second peak, exothermic, one corresponding to the contraction during the heating of the alloy in question, in the field $\left[50^{\circ} \mathrm{C}-400^{\circ} \mathrm{C}\right]$, is probably due to the appearance of the metastable phase $\eta$ ' quoted by Mondolfo et al. [8].

- The third exothermic peak recorded on the DSC curve during heating of the alloy, corresponds perfectly to the second expansion observed by dilatometry. This is certainly related to the formation of the stable phase $\eta$ (MgZn) [9-11].

\subsection{Influence of Thermomechanical Treatments on the Expansion Curves Heat of the Alloy Al-5.8\%Zn-2.7\%Mg}

The Figure 4 shows the variation of the linear coefficient of thermal expansion $\alpha$ of the alloy $\mathrm{Al}-5.8 \% \mathrm{Zn}-2.7 \% \mathrm{Mg}$ as a function of temperature in the interval $\left[50^{\circ} \mathrm{C}-400^{\circ} \mathrm{C}\right]$ for the three structural states studied (Gross, homogenized and Homogenized + Garbled).

It also notes that there is a slight shift in the temperature ranges corresponding to these phase transformations. The latter depend on the history of the material before income and this confirms the work of Deschamps [5] and Benabdoun [6].

\subsection{Influence of Thermomechanical Treatments on the DSC Curves Alloy Al-5.8\%Zn-2.7\%Mg}

Examination of the DSC thermograms (Figure 5) con-

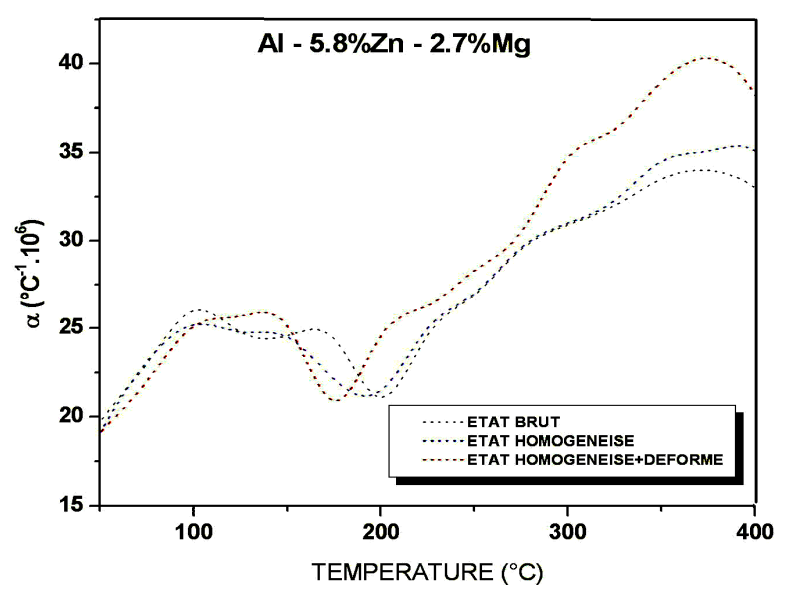

Figure 4. Variation of $\alpha$ as a function of $T{ }^{\circ} \mathrm{C}$ of the alloy $\mathrm{Al}-5.8 \% \mathrm{Zn}-2.7 \% \mathrm{Mg}$ for the three structural states.

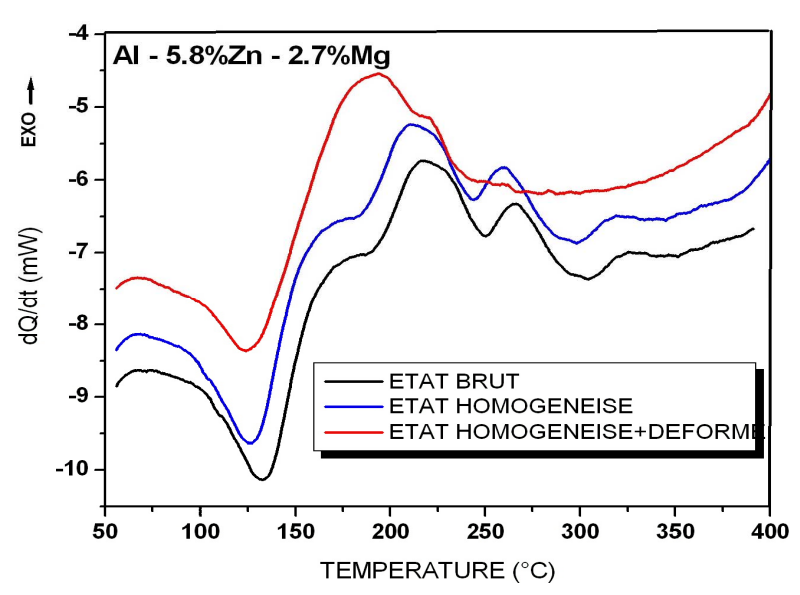

Figure 5. Variation of the DCS as a function of $\boldsymbol{T}^{\circ} \mathrm{C}$ of the $\mathrm{Al}-5.8 \% \mathrm{Zn}-2.7 \% \mathrm{Mg}$ alloy for the three structural states.

firms, quite clearly, the existence of at least three (03) of these changes occurred during the tempering, the appearance of three different peaks, while giving us additional information on their intensity and nature of precipitation or dissolution. It is found that these treatments have no significant effect on the dissolution of GP zones (endothermic peak corresponding to the first expansion) and the precipitation of equilibrium phase $\eta(\mathrm{MgZn})$ corresponding to the second exothermic peak corresponding to the second expansion recorded dilatometric curves. For cons, the effects of heat treatment and homogenization in particular those associated with plastic deformation are visible by a shift to higher temperatures low precipitation of the metastable phase $\eta^{\prime}$. This is mainly due to defects introduced during plastic deformation that significantly enhance decomposition of the supersaturated solid solution. The increase in the number of gaps facilitates the diffusion of atoms of magnesium and zinc, and the high density of dislocations stimulates diffusion along the channels of dislocations. Thus the activation energy of 
the reaction of precipitation of deformed samples is much lower than that of samples with little or no distortion. Therefore the process of germination and growth of new phases are favored.

On the other hand, the plastic deformation introduced a supersaturated solid solution already containing an excess of defects due to the rapid quenching, further increasing their density, and therefore encourages a greater degree than the different phase transformations may occur during heating of the material. This explains why the phenomena related to the dissolution of the zones, and precipitation of two phases $\eta^{\prime}$ and $\eta$ occur earlier, at lower temperatures than for the case of the raw material and/homogenized or that generally observed in various aluminum alloys 7000 series.

\section{Conclusions}

The great diversity of phases present in alloys Al-Zn-Mg makes this system very complex. They are likely to improve physical properties by hardening or otherwise alter significantly.

- Both technical analysis of thermodynamic properties namely dilatometry and calorimetry may give us additional information on the nature and sequence of the various phenomena of precipitation or dissolution of phases present during the tempering of the alloy studied in the temperature range $\left[50^{\circ} \mathrm{C}-400^{\circ} \mathrm{C}\right]$.

- There is a great similarity between the curves of thermal expansion and calorimetric study of the alloy.

- The first three transformations observed by the dilatometer technique namely the first two expansions and the only contraction are directly related to the appearance of different peaks recorded on the DSC curves.

- The first expansion is directly related to one endothermic peak appears on the DSC curves, it is certainly due to the dissolution of GP zones.

- The only contraction experienced by the material during tempering is represented by the first exothermic peak, the latter is due to the appearance of the metastable phase $\eta$ '.

- The second expansion corresponding to the second exothermic peak may be due to the appearance of the stable phase $\eta(\mathrm{MgZn})$.

- The effects of heat treatment and homogenization in particular those associated with plastic deformation are highlighted by a shift toward lower temperatures of the precipitation of metastable phase $\eta$ '.

\section{REFERENCES}

[1] A. Deschanps, F. Livet and F. Bréchet, "Influence of Predeformation on Ageing in an Al-Zn-Mg Alloy," Acta Materialia, Vol. 47, No. 1, 1999, pp. 281-292.

[2] M. Benabdoun, "Thèse de Doctorat, Microstructure et Propriétés des Alliages D'aluminium," Université de Constantine, Algérie, 2004.

[3] A. Deschanps, "Thèse de Doctorat, Influence de la Prédéformation et des Traitements Thermiques sur la Microstructure et les Propriétés Mécaniques des Alliages AlZn-Mg-Cu," Institut Polyclinique de Grenoble, 1997.

[4] M. Benabdoun and D. Tahar, "Smail Hamamda Article Etude Dilatomètrique de L'alliage Al-6\%Zn-3\%Mg," université de Constantine, Algérie, 2007.

[5] R. M. Allen and J. B. Vander Sande, "The Oriented Growth of Precipitates on Dislocations in Al-Zn-Mg," Acta Materialia, Vol. 28, No. 9, 1980, pp. 1185-1189. doi:10.1016/0001-6160(80)90074-7

[6] P. Gomiero, Proceeding of 4th Intern Conference on Aluminium Alloys, Atlanta, 11-16 September 1994, pp. 644-651.

[7] R. W. Balluffi, "Annealing Kinetics of Voids and the Self-Diffusion Coefficient in Aluminum," Physica Status Solidi, Vol. 42, No. 4, 1970, pp. 11-17. doi:10.1002/pssb.19700420102

[8] S. Ceresara and P. Fiorini, "Effect of Si Excess on the Ageing Behaviour of Al- $\mathrm{Mg}_{2} \mathrm{Si} 0.8 \%$ Alloy Mater," Science \& Engineering, Vol. 5, No. 4, 1972, pp. 220-227. doi:10.1016/0025-5416(70)90084-4

[9] S. Komatsu, et al., "Influence of Predeformation on Ageing in an Al-Zn-Mg Alloy-I. Microstructure Evolution and Mechanical Properties," Acta Materialia,Vol. 47, No. 1, 1998, pp. 281-292. doi:10.1016/S1359-6454(98)00293-6

[10] L. S. Mondolfo, N. A. Gjostein and D. W. Lewinson, "Microstructural Evolution and Age Hardening in Aluminium Alloys: Atom Probe Field-Ion Microscopy and Transmission Electron Microscopy Studies," Materials Characterization, Vol. 44, No. 1, 2000, pp. 101-131.

[11] A. J. De Ardo and J. R. Simensen, "A Structural Investigation of Multiple Aging of Al-7-wt\% Zn-2.3-wt\% Mg," Metallurgical and Materials Transactions B, Vol. 4, No. 10, 1973, pp. 2413-2421. 